\title{
PREVALENCE, ANTIBIOGRAM AND BIOFILM PRODUCTION OF LISTERIA MONOCYTOGENES FROM FAECES AND FOETUSES OF SLAUGHTERED PREGNANT COWS: ENVIRONMENTAL AND PUBLIC HEALTH IMPLICATIONS
}

\author{
Adesokan, H. K., Kehinde, E. G. \\ Department of Veterinary Public Health and Preventive Medicine \\ University of Ibadan, Ibadan \\ Nigeria \\ greaterglory2008@gmail.com
}

\section{ABSTRACT}

The indiscriminate slaughter of pregnant animals which characterizes most developing countries poses increasing environmental and public health risks from Listeria monocytogenes infections which are endemic in such settings. The available reports show increasing trends of Listeria monocytogenes infections in both humans and animals in Nigeria. This study examined the prevalence, antibiogram and biofilm production of L. monocytogenes from faeces and foetuses of slaughtered pregnant cows in Ibadan Central Abattoir, Nigeria. Faecal $(n=118)$ and foetal $(n=118)$ swabs were cultured and isolates tested for antibiotic susceptibility by Kirby-Bauer assay, while biofilm production was quantified following the standard procedures. The data were analysed using the Chi Square and Student's t-test at $\mathbf{P}<0.05$. Listeria monocytogenes were isolated from five $(4.2 \%)$ and three $(2.5 \%)$ faeces and foetus swabs, respectively, without significant association with sample type $(P=0.50)$. The isolates were resistant to all the antibiotics tested except gentamicin; with significantly higher production of biofilm by those from foetal samples $(P=0.012)$. The detection of widespread antibiotic-resistant L. monocytogenes from faeces and foetuses has important environmental and public health implications, given the risk of contamination through faecal shedding and foetal handling. The biofilm production by the pathogen connotes its ability to persist in the environment, suggestive of the challenging effects to its control. Campaigns against indiscriminate slaughter of pregnant animals, and proper hygiene are advocated to ultimately safeguard human and animal health.

Key words: abattoir; antibiotic resistance; Listeria monocytogenes; prevalence; public health

\section{INTRODUCTION}

Listeria monocytogenes is a facultative intracellular pathogen which causes infectious disease in many different animal species, especially in farm ruminants [37] as well as humans. Foetuses from pregnant infected animals are 
very rich in L. monocytogenes [18]. Similarly, faeces play a significant role in the spread of listeriosis to humans and animals [35]. It is associated with severe foodborne infections in humans; thus, this organism is considered one of the most important pathogens responsible for foodborne infections. Listeriosis, caused by L. monocytogenes is a zoonotic disease which poses health risk to the immunocompromised and occupationally exposed individuals including abattoir workers and surrounding environments. In the present decennium, numerous serious outbreaks of foodborne listeriosis have been recorded in different countries and continents $[23,31,51,52]$, causing serious manifestations in the form of septicaemia and meningitis, principally in the immunocompromised and old populaces in addition to pregnant women, who may bring forth stillborn babies or seriously contaminated infants $[29,55]$.

These associated health problems could be more challenging particularly in most developing countries including Nigeria characterized with indiscriminate use of antibiotics in animals and consequent widespread cases of antibiotic resistance $[3,14]$. Considering the delayed health care-seeking behaviour of abattoir workers and most rural dwellers in the surrounding environments, coupled with other associated immunocompromising practices, these occupationally and environmentally exposed individuals may be the worst hit. More so, the risk of zoonotic transmission of L. monocytogenes in the abattoir and surrounding environments could be potentiated since the organism could colonize surfaces, forming biofilms that remain attached to equipment used in food production [46]. Unfortunately, most abattoir workers in the country generally do not observe proper hygiene when processing slaughtered animals and are thus exposed, while serving as a source infection to others in their communities. Also, poor disposal of animal faeces which are often washed off into the surrounding environments threatens environmental health. As reported, cattle and many other mammals including humans, can be asymptomatic shedders of the pathogen [54].

In order to assess the magnitude of this risk, we sought to determine the prevalence, antibiotic susceptibility profiles and biofilm production of Listeria monocytogenes in slaughtered pregnant cows in Ibadan Central Abattoir, southwestern Nigeria.

\section{MATERIALS AND METHODS}

\section{Study setting}

This cross-sectional study was carried out at the Ibadan Central Abattoir, Ibadan, southwestern Nigeria between May and December, 2018. Ibadan is the third most populous city in the country and the largest by area. It has a population of over 3 million people. The city is projected to increase to about 5.03 million inhabitants by 2025, considering an average annual growth rate of $4.6 \%$ during the period 2010-2020 [50]. Ibadan Central Abattoir was chosen as it is the only abattoir in the city recognized by the government of the state where food animals are slaughtered. It slaughters an average of 450 heads of cattle per day aside from goats, sheep and pigs and has the capacity of holding a human population of about 800 people. The abattoir supplies meat to the entire citizenry of the city and neighbouring environments. It thus provides a milieu for zoonotic transmission of diseases given the human-animal interface in the setting, coupled with unguarded contacts between humans and animals as well as poor hygienic practices of the abattoir workers.

\section{Study population and sample size}

The study population included all slaughtered pregnant cows at the abattoir during the period of study. Pregnancy state in the slaughter animal population was determined following evisceration after slaughter, since routine ante-mortem examination was not enabled in the setting. Following the $6.9 \%$ prevalence of L. monocytogenes in livestock animals [26], sample size was calculated using the formula by Thrusfield [49]. This gave a minimum sample size of 110 animals including the addition of $10 \%$ level of attrition.

\section{Animal sampling}

The purposive sampling technique was used in the collection of samples by sampling every identified pregnant cow slaughtered on each day of visit to the abattoir. Swabs of foetuses and faeces of every slaughtered pregnant cow were aseptically collected using sterile swabs sticks. These samples, upon collection were immediately placed in swab stick casings containing listeria transport medium (Oxoid Limited, United Kingdom). All the samples were collected following this procedure each day of the visit to the abattoir until the sample size was reached. The abattoir was 
visited twice a week throughout the period of the study. Upon collection each day, the swab samples were transported in a transporting flask containing icepack to the Bacterial Zoonoses Laboratory of the Department of Veterinary Public Health and Preventive Medicine, University of Ibadan for processing. Samples were processed within three hours post-collection.

\section{Sample processing}

A $10^{5}$-fold serial dilution of the samples was carried out. Thereafter, the samples were incubated at $37^{\circ} \mathrm{C}$ for 18 to 24 hours and then plated on Listeria selective agar (Oxoid Limited, United Kingdom). After inoculation onto the agar, the Petri dishes were turned upside down and incubated at $37^{\circ} \mathrm{C}$ for 24 to 48 hours. After incubation, the growth on the medium were observed. On the primary medium used, the most distinct colonies showing perfect characteristics of Listeria were picked and aseptically sub-cultured in freshly prepared Listeria selective medium and incubated to obtain pure colonies. This was done as soon as possible to ensure optimum viability of the organisms. After the second round of culture on the selective medium, the bacterial colonies on the media were then aseptically stored on a nutrient agar slant (Oxoid Limited, United Kingdom) and refrigerated. The L. monocytogenes were identified following the earlier described protocols [15] using conventional biochemical methods which included Gram staining, catalase, aesculin, triple sugar iron (TSI) reaction, motility, urease, sugar fermentation tests (lactose, sucrose, mannitol and xylose), motility and CAMP tests.

\section{Antibiotic susceptibility testing}

All of the L. monocytogenes isolates obtained were subjected to antibiotic susceptibility testing by the disk diffusion method as described by Clinical and Laboratory Standards Institute [20]. Briefly, $3 \mathrm{ml}$ of sterile normal saline was used to emulsify an inoculum of each pure bacterial isolate and the density was then adjusted to the $0.5 \mathrm{Mc}$ Farland standard. Using a sterile cotton swab dipped into the standardized suspension of bacterial cultures, inoculations were made into the Mueller-Hilton Agar (MHA) plates (Oxoid, England). The plates were then allowed to dry. Antibiotic disk containing amikacin $(30 \mu \mathrm{g})$, cefotaxime $(30 \mu \mathrm{g})$, ceftriaxone $(30 \mu \mathrm{g})$, cefuroxime $(30 \mu \mathrm{g})$, gentamicin $(10 \mu \mathrm{g})$, vancomycin $(10 \mu \mathrm{g})$, tetracycline $(30 \mu \mathrm{g})$, co-trimoxazole $(25 \mu \mathrm{g})$, ciprofloxacin $(5 \mu \mathrm{g})$, meropenem
$(10 \mu \mathrm{g})$, chloramphenicol (30 $\mu \mathrm{g})$ (Antibiotic Becton Dickinson and Company, Sparks, USA) were placed onto MHA plates.

These antimicrobial agents were chosen on the basis of their importance in treating human or animal Listeria infections; their use in animals and on the basis of their ability to provide diversity for representation of different antimicrobial agent classes. The plates were thereafter incubated at $37^{\circ} \mathrm{C}$ for 24 hours. The zone of inhibition was measured in millimetres and zone diameters were interpreted as susceptible, intermediate and resistant with respect to standards on the basis of the critical points recommended [20]. L. monocytogenes ATCC7644 was used as a reference strain.

\section{Biofilm production and quantification}

Biofilm production and quantification by the identified L. monocytogenes were done according to an earlier described procedure [42]. One colony of each overnight grown L. monocytogenes culture were transferred into $9 \mathrm{ml}$ tryptose soy broth (Oxoid Limited, United Kingdom) and incubated at $37^{\circ} \mathrm{C}$ for $24 \mathrm{~h}$ was used for the biofilm formation on the glass vials [42]. Non-inoculated tryptose soy broth served as the negative control. The glass vials $(4.5 \times 191.4 \mathrm{~cm}$; Fisher Scientific) which were used as glass surface were washed with alkaline detergent (Alconox ${ }^{\oplus}$ ) and rinsed thoroughly using deionized water. They were thereafter air-dried and then autoclaved at $121^{\circ} \mathrm{C}$ for $30 \mathrm{~min}$. Then, $5 \mathrm{ml}$ of the pure cultures were placed into the glass vials and incubated at $37^{\circ} \mathrm{C}$ for $24 \mathrm{~h}$ in order to allow the cells in the broth to attach to the glass vials. The glass vials were covered with lids in order to prevent evaporation of the broth. Following the incubation period, quantification of L. monocytogenes attached to glass surface was done using a crystal violet binding assay [42] with some slight modifications. The broth cultures were withdrawn and the glass vials were rinsed three times with sterile distilled water to remove loosely attached cells.

Using a Bunsen burner, the glass vials were air-dried and fixed by passing them over the flame three times. Thereafter, the fixed cells on the surfaces were stained with $2 \mathrm{ml}$ of $1 \%$ crystal violet (Fisher Scientific, United States) for $1 \mathrm{~min}$. The glass vials were placed under running tap water in order to rinse off excess stain until there was no visible stain in the washed water. Further, the glass vials were air-dried for $5 \mathrm{~min}$ at $60^{\circ} \mathrm{C}$. The dye bound to the 
adherent cells was re-solubilized using $200 \mu \mathrm{l}$ of $33 \%$ (v/v) acetic acid per vial. Each of the isolates were run in triplicate. The optical density (OD) of each of the glass vials and the controls were measured at $450 \mathrm{~nm}$ using a spectrophotometer (Novaspec II). To determine the actual value, the absorbance of the negative control was subtracted from the absorbance values [42] and the means of the respective values were obtained for each isolate.

\section{Data analysis}

The data obtained were coded in Microsoft excel and subjected to descriptive statistics. Frequencies and percentages were calculated as appropriate for the prevalence of L. monocytogenes per sample type. Chi-square was used to test for association between outcome variable (L. monocytogenes positivity) and sample type. The Student's t-test was used to compare the means of biofilm produced by L. monocytogenes between faecal and foetal samples using STATA 12.0 software. The level of significance was put at $\mathrm{P} \leq 0.05$.

\section{RESULTS}

\section{Isolation and identification of Listeria monocytogenes}

A total of 236 samples were collected, 118 each from faeces and foetuses. Of these, Listeria spp. were present in $95(80.5 \%)$ and $79(66.9 \%)$ of the cow faecal and foetal swabs, respectively. The mean count for the faecal swabs was $0.532 \pm 0.24 \log \mathrm{CFU} \cdot \mathrm{ml}^{-1}$, with the highest and lowest counts being $1.839 \log$ and $0.30 \log$ CFU.ml ${ }^{-1}$, respectively. The mean count for the foetal swabs was $1.136 \pm 0.32 \log \mathrm{CFU} \cdot \mathrm{ml}^{-1}$, with the highest and lowest counts being 1.477 $\log$ CFU.ml ${ }^{-1}$ and $0.301 \log$ CFU.ml ${ }^{-1}$, respectively. Further, $5(4.2 \%)$ and $3(2.5 \%)$ of the total samples obtained from faecal and foetal swabs, respective- ly, were confirmed as L. monocytogenes, with one isolate per sample (Table 1). Overall, a total of eight L. monocytogenes isolates were obtained.

\section{Antibiotics susceptibility}

The mean disk diffusion zones obtained indicated that the L. monocytogenes isolates from the faecal samples showed reduced susceptibility (as measured by disk diffusion zone sizes) compared to foetal sample isolates for amikacin, gentamicin and chloramphenicol (Table 2).

All the isolates from both faecal and foetal swabs exhibited $100 \%$ resistance to all the antibiotics tested except to gentamicin where $60.0 \%$ and $40.0 \%$ intermediate resistance and susceptibility were recorded for isolates from faecal samples as well as $100 \%$ susceptibility for foetal isolates. Similarly, $80.0 \%$ and $20.0 \%$ of the faecal isolates as well as $66.7 \%$ and $33.3 \%$ of the foetal isolates demonstrated resistance and intermediate resistance, respectively to chloramphenicol (Table 3).

\section{Biofilm production}

The means and standard error of the means of the biofilm production by the L. monocytogenes from faecal and foetal swabs are presented in Table 4 . It revealed that the strains from the foetal swabs produced significantly higher quantity of biofilm than those from the faecal samples $(\mathrm{P}=0.012)$.

\section{DISCUSSION AND CONCLUSIONS}

Listeria monocytogenes constitutes a serious global public health threat, with food animals and their products serving as the most important vehicles for the majority of cases of infections $[34,36]$. The present study was performed at the Ibadan Central Abattoir, southwestern Ni-

Table 1. Prevalence of Listeria spp. and Listeria monocytogenes from faeces and foetuses of slaughtered pregnant cows at Ibadan Central Abattoir, Ibadan, southwestern Nigeria

\begin{tabular}{ccccc}
\hline $\begin{array}{c}\text { Type } \\
\text { of samples }\end{array}$ & $\begin{array}{c}\text { No. of samples } \\
\text { collected }\end{array}$ & $\begin{array}{c}\text { Listeria spp. } \\
\mathrm{n}[\%]\end{array}$ & $\begin{array}{c}\text { Mean counts } \\
\text { Log CFU.ml } \\
{[\text {-1 }}\end{array}$ & $\begin{array}{c}\text { Listeria } \\
\text { monocytogenes } \pm \text { SEM] } \\
\mathrm{n}[\%]\end{array}$ \\
\hline Faecal swabs & 118 & $95(81)$ & $0.532 \pm 0.24$ & $5(4.2)$ \\
Foetal swabs & 118 & $79(67)$ & $1.136 \pm 0.32$ & $3(2.5)$ \\
\hline
\end{tabular}


Table 2. Mean disk diffusion zones and resistance breakpoints for Listeria monocytogenes from faecal and foetal swabs of slaughtered pregnant cows at Ibadan Central Abattoir, southwestern Nigeria

\begin{tabular}{lccc}
\hline \multicolumn{1}{c}{ Antibiotics } & Breakpoint $[\mathrm{mm}]$ & \multicolumn{2}{c}{ Mean disk diffusion zone of inhibition [mm] } \\
\cline { 3 - 4 } & & *Faeces $[\mathrm{n}=5]$ & Foetus $[\mathrm{n}=3]$ \\
\hline AMK (amikacin) & $\leq 14$ & 11 & 13 \\
CTX (cefotaxime) & $\leq 14$ & 0.0 & 0.0 \\
CTR (ceftriaxone) & $\leq 19$ & 0.0 & 0.0 \\
CRX (cefuroxime) & $\leq 14$ & 0.0 & 0.0 \\
GEN (gentamicin) & $\leq 12$ & 14.2 & 20 \\
VAN (vancomycin) & - & 0.0 & 0.0 \\
TET (tetracycline) & $\leq 14$ & 5 & 0.0 \\
COT (co-trimoxazole) & $\leq 10$ & 0.0 & 0.0 \\
CIP (ciprofloxacin) & $\leq 15$ & 0.0 & 0.0 \\
MEM (meropenem) & $\leq 13$ & 0.0 & 0.0 \\
CHL (chloramphenicol) & $\leq 12$ & 8 & 10 \\
\hline
\end{tabular}

${ }^{*} \mathrm{n}$-Number of Listeria monocytogenes isolates

Table 3. Resistance/susceptibility of $L$. monocytogenes isolated from faecal and foetal swabs of slaughtered pregnant cows in Ibadan, Nigeria

\begin{tabular}{|c|c|c|c|c|c|c|c|c|c|}
\hline \multirow{3}{*}{ Antibiotics } & \multirow{2}{*}{\multicolumn{3}{|c|}{ *Breakpoints [mm] }} & \multicolumn{6}{|c|}{ Isolate [\%] } \\
\hline & & & & \multicolumn{3}{|c|}{ **Faeces $[n=5]$} & \multicolumn{3}{|c|}{ Foetus $[n=3]$} \\
\hline & $\mathrm{R}$ & 1 & $S$ & $\mathrm{R}$ & I & $S$ & $\mathrm{R}$ & I & $S$ \\
\hline Amikacin & $\leq 14$ & $15-16$ & $\geq 17$ & 80 & 20 & 0.0 & 66.7 & 33.3 & 0.0 \\
\hline Cefotaxime & $\leq 14$ & $15-22$ & $\geq 23$ & 100 & 0.0 & 0.0 & 100 & 0.0 & 0.0 \\
\hline Ceftriaxone & $\leq 13$ & $14-20$ & $\geq 21$ & 100 & 0.0 & 0.0 & 100 & 0.0 & 0.0 \\
\hline Cefuroxime & $\leq 14$ & $15-22$ & $\geq 23$ & 100 & 0.0 & 0.0 & 100 & 0.0 & 0.0 \\
\hline Gentamicin & $\leq 12$ & $13-14$ & $\geq 15$ & 0.0 & 60 & 40 & 0.0 & 0.0 & 100 \\
\hline Vancomycin & - & - & - & 100 & 0.0 & 0.0 & 100 & 0.0 & 0.0 \\
\hline Tetracycline & $\leq 14$ & $15-18$ & $\geq 19$ & 100 & 0.0 & 0.0 & 100 & 0.0 & 0.0 \\
\hline Co-trimoxazole & $\leq 10$ & $11-15$ & $\geq 16$ & 100 & 0.0 & 0.0 & 100 & 0.0 & 0.0 \\
\hline Ciprofloxacin & $\leq 15$ & $16-20$ & $\geq 21$ & 100 & 0.0 & 0.0 & 100 & 0.0 & 0.0 \\
\hline Meropenem & $\leq 13$ & $14-15$ & $\geq 16$ & 100 & 0.0 & 0.0 & 100 & 0.0 & 0.0 \\
\hline Chloramphenicol & $\leq 12$ & $13-17$ & $\geq 18$ & 80 & 20 & 0.0 & 66.7 & 33.3 & 0.0 \\
\hline
\end{tabular}

${ }^{*} \mathrm{R}$-Resistant; I-Intermediate; $\mathrm{S}$-Susceptible; ${ }^{* *} \mathrm{n}$-Number of Listeria monocytogenes isolates

Table 4. Biofilm quantification of Listeria monocytogenes from faecal and foetal samples (450 nm)

\begin{tabular}{ccc}
\hline Isolates from faecal swab samples & Mean \pm SD & P value \\
\hline $101 \mathrm{~A}$ & $0.046 \pm 0.01$ & \\
$57 \mathrm{~A}$ & $0.046 \pm 0.01$ & \\
$99 \mathrm{~A}$ & $0.044 \pm 0.01$ & \\
$39 \mathrm{~A}$ & $0.045 \pm 0.01$ & \\
$63 \mathrm{~A}$ & $0.047 \pm 0.01$ & \\
\hline Isolates from foetal swab samples & & \\
\hline $54 \mathrm{~B}$ & $0.012 \pm 0.01$ & \\
$36 \mathrm{~B}$ & $0.049 \pm 0.01$ & \\
$65 \mathrm{~B}$ & $0.048 \pm 0.01$ & \\
\hline
\end{tabular}


geria, an animal processing facility which is increasingly recognized as a melting pot for food pathogens. The cattle being slaughtered at the abattoir are mostly trade animals drawn from different farms across the country and are often transhumant in nature, moving from one point to the other in search of water and pasture. Importantly, this study observed a higher prevalence of L. monocytogenes from faecal than foetal swab samples, with the strains isolated being resistant to the majority of antibiotics studied, as well as, all being biofilm formers. Hence, strong social and commercial links between such mobile cattle herds and the local communities, their transverse can contribute to efficient distributions of the zoonotic agent from animals to humans [53]. Besides, the strong exposure of the abattoir workers and the surrounding abattoir environment to this pathogen is a matter of serious public health concern.

Our findings reiterate cattle as an important carrier of L. monocytogenes and agree with previous reports that this foodborne pathogen is quite prevalent in animals and their products $[9,30,38]$. More specifically, this study demonstrated that cow faeces and foetuses remained a potential source of L. monocytogenes infection to meat processors and handlers. This is in line with the study [25] that reported cattle as a potentially important reservoir for L. monocytogenes. The present finding is of serious public health importance given the poor hygienic practices of most abattoir workers [27]. Cross contamination of carcasses with faeces and unhygienic handling of foetuses from slaughtered pregnant animals during animal processing is a common occurrence particularly in developing countries. Thus, both the meat processors, and consumers through contaminated meat are potentially exposed to the infection. It is also plausible that the cattle might have been shedding the organisms while in the respective herds from which they were sourced, thus exposing both livestock handlers and other animals to the infection and also causing environmental contamination.

In addition, the bacterial isolation of L. monocytogenes from foetuses of slaughtered pregnant cows in this study portends public health challenges considering the reported practice of eating and selling gravid uterus and foetuses as meat in Nigeria [4]. This concern is potentiated by the practice of eating raw or improperly cooked meat which is common amongst meat handlers in the country $[5,28]$ and amongst Africans in general $[32,48]$. As such, there is a high risk of human infection with L. monocytogenes among these meat handlers and other potential consumers. In addition, poor meat/food handling practices characteristic of meat handlers and most households in developing countries, including Nigeria [7, 17], could as well, enhance the transmission of L. monocytogenes. A previous report has shown that food contamination from raw meat remains an important cause of foodborne disease outbreaks or food poisoning [44]. Such contaminations do occur when food that does not require cooking such as salad is prepared on the same chopping board already used to prepare raw meat without adequate washing [1]. Cross-contamination can also occur when raw meat is stored above ready-to-eat meals. Thus, the practice of selling foetuses to and poor hygienic handling by unsuspecting buyers connotes considerable public health issues.

Besides, the fate of cow faeces from slaughtered cattle in the abattoir is a matter of concern. Most abattoirs in Nigeria lack adequate facilities for proper waste handling and disposal. As a result, the faeces and other wastes generated from slaughter processes are often disposed of around the abattoir premises, thereby constituting social, environmental and public health hazards to the surrounding environments. More importantly, during the rainy season, these waste materials are washed off, traversing kilometres away from the abattoir and contaminating water wells, thus exposing such neighbouring environments to bacterial contaminations. A d e s o k a n, S u la i m o n [8] revealed in their study that almost $75 \%$ of slaughterhouse workers in a major meat processing facility in Ibadan, Nigeria discharged slaughterhouse wastewater into surrounding streams. Such a practice as previously reported, could contaminate surface and underground waters [2] with resultant pathogenic organisms, including L. monocytogenes in surrounding well water $[11,24]$. This practice inadvertently impacts with associated severe health risk to such poor communities located near the river which use it for domestic activities, such as cooking, washing, and bathing [8]. Further, the practice of using cow faeces as manure in farming in Nigeria portends a matter of public health importance as the pathogens could be transmitted from one place to the other with potential effects on both crops and humans. Vegetables, for instance have been identified as a major vehicle for listeriosis due to their direct contamination with decaying vegetation, soil surfaces, rivers, animal faeces used as manure, and effluents from sewage treatments, improper harvesting and handling procedures, 
improper sanitary conditions of equipment, and transportation practices $[16,19]$. Previous studies have reported isolation of L. monocytogenes from vegetables [10, 45].

Furthermore, the levels of resistance exhibited to the antibiotics used in this study calls for public health action. Since the majority of these antibiotics are commonly shared with humans, the current levels of resistance do imply that such antibiotics might prove ineffective against infections in humans when the need arises. This finding is similar to the reports of other studies $[6,13,47]$ which indicated that L. monocytogenes were highly resistant to important antibiotics. Our observation might be buttressing a previous report of widespread abuse of antibiotics by farmers and animal health workers [12]. In this study, the isolated L. monocytogenes were resistant to amikacin, cefotaxime, cefuroxime, ceftriaxone, tetracycline, vancomycin, co-trimoxazole, ciprofloxacin and meropenem indicating resistance to nine commonly used antibiotics. This is similar to the report of S a r a $\mathrm{n} \mathrm{g} \mathrm{i,} \mathrm{P} \mathrm{a} \mathrm{n} \mathrm{d} \mathrm{a} \mathrm{[47]} \mathrm{whereby} \mathrm{resistance}$ towards oxytetracycline, penicillin G, tobramycin, cefotaxime, cephalexin and ceftriaxone was observed. P e t e $\mathrm{r}$ et al. [43] similarly indicated that 16 isolates of L. monocytogenes from pork, beef, and chicken were resistant to amoxicillin, augmentin, cloxacillin, and tetracycline, although susceptible to gentamicin, co-trimoxazole, erythromycin, and chloramphenicol. Further, L e e et al. [33] reported that all strains of L. monocytogenes which were isolated from ready-to-eat seafood and food processing environments were resistant to benzyl penicillin, clindamycin, and oxacillin.

In this study, all the isolated L. monocytogenes from foetal and faecal swab samples produced biofilms. This is in line with the report [41] that L. monocytogenes can evolve a biofilm and are able to persist in the food processing environment. As previously reported by $\mathrm{O} l \mathrm{a}$ i $\mathrm{m}$ a t et al. [39] in their review of the emergence of antibiotics resistance in L. monocytogenes isolated from food products, most L. monocytogenes strains possess a strong biofilm forming capability. Generally, biofilm forming bacteria pose a great challenge to the food industry because of its inherent resistance to the action of disinfectants; thus, contributing to L. monocytogenes protection against cleaning and sanitation in food processing environment. Biofilms continue to pose concerns to food manufacturers as they are one of the major reasons for limiting the shelf life and favouring pathogen contamination of food products [22]. The growth of biofilms in food processing environment is one of the main sources of repeated bacterial food contaminations [21], making it challenging to control bacterial contaminations in such an environment. Though significantly higher biofilms were produced by the L. monocytogenes from foetal samples, all the isolates obtained in this study produced biofilm. In general, L. monocytogenes in the biofilm state shows a reduced susceptibility to antimicrobial agents [22]. This might explain the observed high level of resistance of L. monocytogenes to the majority of antibiotics evaluated in our present study.

Our findings notwithstanding, this study had some limitations. One, the serotypes of the L. monocytogenes isolated were not determined, as this would have provided more insights into the findings of the study. Two, samples from the abattoir environmental surfaces were not obtained as analysis of such would have enabled comparison of the strains between those isolated from the faecal/foetal samples of the slaughtered animals and those from the environment.

Despite these limitations, the present findings have established a higher prevalence of L. monocytogenes in faeces than foetal swabs, indicating important environmental and public health implications since faecal shedding poses a risk of contamination of the abattoir environment and exposed humans. In addition, the level of resistance to major antibiotics by the isolates is worrisome considering the increasing health challenges the world is facing today with resulting resistance in humans when the need to use such antibiotics arises. This observation of widespread resistance to major antibiotics by L. monocytogenes therefore, requires all hands to be on deck towards mitigating the resulting rise in resistance profile of the pathogen in humans. As reported, it is anticipated that global deaths from infections caused by antibiotic resistant pathogens will increase from 700,000 to 10 million annually, and costs are predicted to reach US $\$ 100$ trillion by 2050 [40]. Formation of biofilm by the L. monocytogenes strains indicates their ability to persist in the abattoir environment, thus resisting sanitizers with attendant challenging effects to its control. The need for extensive educational programme for abattoir workers on proper hygiene and against slaughter of pregnant animals is hereby advocated. 


\section{REFERENCES}

1. Abdul-Mutalib, N., Abdul-Rashid, M., Mustafa, S., Amin-Nordin, S., Hamat, R. A., Osman, M., 2012: Knowledge, attitude and practices regarding food hygiene and sanitation of food handlers in Kuala Pilah, Malaysia. Food Control, 27, 289-293. DOI: 10.1016/j.foodcont.2012.04.001.

2. Abiade-Paul, C. U., Kene, I. C., Chah, K. F., 2006: Occurrence and antibiogram of salmonellae in effluent from Nsukka Municipal Abattoir. Nig. Vet. J., 1, 48-53.

3. Adesokan, H. K., Akinseye, V. O., Adesokan, G. A., 2015: Food safety training is associated with improved knowledge and behaviour among foodservice establishments' workers. Int. J. Food Sci., Article ID 328761, 8 pp. DOI: 10.1155/2015/ 328761 .

4. Adesokan, H. K., Alabi, P. I., Ogundipe, M. A., 2016: Prevalence and predictors of risk factors for brucellosis transmission by meat handlers and traditional healers' risk practices in Ibadan, Nigeria. J. Prev. Med. Hyg., 57, 3, E164-E171.

5. Adesokan, H. K., Alabi, P. I., Stack, J. A., Cadmus, S. I. B., 2013: Knowledge and practices related to bovine brucellosis transmission amongst livestock workers in Yewa, SouthWestern Nigeria. J. South Afr. Vet. Assoc., 84, 1, Art. No. 21, 5 pp. DOI: 10.4102/jsava.v84i1.121.

6. Adesokan, H. K., Funso-Adu, K., Okunlade, O. A., 2020: Foodborne pathogens on meat stored in major central cold rooms in Ibadan and their susceptibility to antimicrobial agents. Folia Vet., 64, 2, 1-10. DOI: 10.2478/fv-2020-0011.

7. Adesokan, H. K., Raji, Q., 2014: Safe meat-handling knowledge, attitude and practices of private and government meat processing plants' workers: implications for future policy. J. Prev. Med. Hyg., 54, 10-16. DOI: 10.15167/2421-4248/ jpmh2014.55.1.419.

8. Adesokan, H. K., Sulaimon, M. A., 2014: Poor slaughterhouse waste management: empirical evidences from Nigeria and implications on achieving millennium development goals. AFRREV Int. J. Sci. Tech., 3, 1, 110-127.

9. Adetunji, V. O., Adedeji, A. O., Kwaga, J., 2014: Assessment of the contamination potentials of some foodborne bacteria in biofilms for food products. Asian Pac. J. Trop. Med., 7 (Suppl 1), S232-S237. DOI: 10.1016/S1995-7645(14)60238-8.

10. Ajayeoba, T. A., Atanda, O. O., Obadina, A. O., Bankole, M. O., Adelowo, O. O., 2015: The incidence and distribution of Listeria monocytogenes in ready-to-eat vegetables in SouthWestern Nigeria. Food Sci. Nutr., 4, 1, 59-66. DOI: 10.1002/ fsn3.263.
11. Akinro, A. O., Ologunagba, I. B., Yahaya, O., 2009: Environmental implications of unhygienic operation of a city abattoir in Akure, Western Nigeria. ARPN J. Eng. Appl. Sci., 4, $9,60-63$.

12. Alhaji, N. B., Isola, T. O., 2018: Antimicrobial usage by pastoralists in food animals in North-central Nigeria: the associated socio-cultural drivers for antimicrobials misuse and public health implications. One Health, 6, 41-47. DOI: 10.1016/ j.onehlt.2018.11.001.

13. Arslan, S., Ozdemir, F., 2008: Prevalence and antimicrobial resistance of Listeria spp. in homemade white cheese. Food Control, 19, 360-363. DOI: 10.1016/j.foodcont.2007. 04.009 .

14. Awosan, K. J., Ibitoye, P. K., Abubakar, A. K., 2018: Knowledge, risk perception and practices related to antibiotic resistance among patent medicine vendors in Sokoto metropolis, Nigeria. Nig. J. Clin. Pract., 21, 1476-1483. DOI: 10.4103/ njcp.njcp_69_18.

15. Barrow, G. I., Feltham, R. K. A., 1993: Cowan and Steel's Manual for the Identification of Medical Bacteria. 3rd edn., Cambridge University Press, Cambridge, 140-143.

16. Berger, C. N., Sodha, S. V., Shaw, R. K., Griffin, P. M., Pink, D., Hand, P. et al., 2010: Fresh fruit and vegetables as vehicles for the transmission of human pathogens. Environ. Microbiol., 12, 2385-2397. DOI: 10.1111/j.1462-2920. 2010.02297.x.

17. Bloomfield, S. F., Nath, K. J., 2013: Home hygiene in developing countries: prevention of infection in the home and the peri-domestic setting. Training resource for developing countries. Int. Sci. Forum Hyg. http://www.ifh-homehygiene.org/training-best-practice/home-hygiene-developing-countries-prevention-infection-home-and-peri-domest-0, Accessed on 6th June, 2020.

18. Brugere-Picoux, J., 2008: Ovine listeriosis. Small Rum. Res., 76, 12-20. DOI: 10.1016/j.smallrumres.2007.12.022.

19. Centre for Disease Control and Prevention, 2019: Centres for Disease Control and Prevention List of Selected Multistate Foodborne Outbreak Investigations. https://www.cdc.gov/foodsafety/outbreaks/multistate-outbreaks/outbreaks-list.html. Accessed on 25th March, 2019.

20. Clinical and Laboratory Standards Institute, 2019: Performance Standards for Antimicrobial Susceptibility Testing. 29th edn., CLSI supplement M100. Clinical and Laboratory Standards Institute, Wayne, PA, 13 pp.

21. Colagiorgi, A., Bruini, I., Di Ciccio, P. A., Zanardi, E., Ghidini, S., Ianieri, A., 2017: Listeria monocytogenes bio- 
films in the wonderland of food industry. Pathogens, 6, 3, 41 . DOI: 10.3390/pathogens6030041.

22. Di Ciccio, P., Conter, M., Zanardi, E., Ghidini, S., Vergara, A., Paludi, D., 2012: Listeria monocytogenes: Biofilms in food processing. Italian J. Food Sci., 24, 3, 203-213.

23. EFSA BIOHAZ Panel (EFSA Panel on Biological Hazards), 2018: Listeria monocytogenes contamination of ready-to-eat foods and the risk for human health in the EU. EFSA J., 16, 1, 5134. DOI: 10.2903/j.efsa.2018.5134.

24. Elemile, O. O., Raphael, D. O., Omole, D. O., Oloruntoba, E. O., Ajayi, E. O., Ohwavborua, N. A., 2019: Assessment of the impact of abattoir effluent on the quality of groundwater in a residential area of Omu-Aran, Nigeria. Environ. Sci. Euro., 31, 16. DOI: 10.1186/s12302-019-0201-5.

25. Esteban, J. I., Oporto, B., Aduriz, G., Juste, R. A., Hurtado, A., 2009: Faecal shedding and strain diversity of Listeria monocytogenes in healthy ruminants and swine in Northern Spain. BMC Vet. Res., 5, 2. DOI: 10.1186/1746-6148-5-2.

26. Faeji, C. O., Fasoro, A. A., Oni, I. O., Akingbade, A. M., 2016: Assessment of Listeria monocytogenes in unpasteurized milk obtained from cattle in Northern Nigeria. J. Microbiol. Res., 6, 1, 23-27. DOI: 10.5923/j.microbiology.20160601.04.

27. Fasanmi, O. G., Makinde, G. E. O., Popoola, M. A., Fasina, O. F., Matere, J., Kehinde, O. O., 2018: Potential risk factors associated with carcass contamination in slaughterhouse operations and hygiene in Oyo State, Nigeria. Int. J. Lives. Prod., 9, 8, 211-220. DOI: 10.5897/IJLP2018.0491.

28. Hambolu, D., Freeman, J., Taddese, H. B., 2013: Predictors of bovine TB risk behaviour amongst meat handlers in Nigeria: a cross-sectional study guided by the health belief model. PLOS ONE, 8, 2, e56091. DOI: 10.1371/journal.pone. 0056091.

29. Henriques, A. R., Cristino, J. M., Fraqueza, M. J., 2017: Genetic characterization of Listeria monocytogenes isolates from industrial and retail ready-to-eat meat-based foods and their relationship with clinical strains from human listeriosis in Portugal. J. Food. Prot., 80, 551-560. DOI: 10.4315/0362028X.JFP-16-310.

30. Ishola, O. O., Mosugu, J. I., Adesokan, H. K., 2016: Prevalence and antibiotic susceptibility profiles of Listeria monocytogenes contamination of chicken flocks and meat in Oyo State, south-western Nigeria: Public health implications. J. Prev. Med. Hyg., 57, 3, E157-E163.

31. Jennison, A. V., Masson, J. J., Fang, N. X., Graham, R. M., Bradbury, M. I., Fegan, N., 2017: Analysis of the Listeria monocytogenes population structure among isolates from 1931 to 2015 in Australia. Frontier Microbiol., 8, Article 603, 1-13. DOI: $10.3389 /$ fmicb.2017.00603.

32. John, K., Fitzpatrick, J., French, N., Kazwala, R., Kambarage, D., Mfinanga, G. S., 2010: Quantifying risk factors for human brucellosis in rural northern Tanzania. PLOS ONE, 5, e9968-e9968. DOI: 10.1371/journal.pone.0009968.

33. Lee, D. Y., Ha, J. H., Lee, M. K., Cho, Y. S., 2017: Antimicrobial susceptibility and serotyping of Listeria monocytogenes isolated from ready-to-eat seafood and food processing environments in Korea. Food Sci. Biotechnol., 26, 1, 287-291. DOI: 10.1007/s10068-017-0038-x.

34. Martínez-Gonzáles, N. E., Martínez-Chávez, L., Cabrera-Díaz, E., Martínez-Cárdenas, C., Gutiérrez-González, P., Castillo, A., 2016: Use of a novel medium, the polymyxin ceftazidime Oxford medium, for isolation of Listeria monocytogenes from raw or non-pasteurized foods. Food Microbiol., 55, 105-111. DOI: 10.1016/j.fm.2015.10.015.

35. Matto, C., Varela, G., Braga, V., Vico, V., Gianneechini, R. E., Rivero, R., 2018: Detection of Listeria spp. in cattle and environment of pasture-based dairy farms. Pesq. Vet. Brasil., 38, 9, 1736-1741. DOI: 10.1590/1678-5150-pvb-5663.

36. Mehmeti, I., Bytyqi, H., Muji, S., Nes, I. F., Diep, D. B., 2017: The prevalence of Listeria monocytogenes and Staphylococcus aureus and their virulence genes in bulk tank milk in Kosovo. J. Infect. Dev. Ctries., 11, 247-254. DOI: 10.3855/ jidc. 8256 .

37. Nightingale, K. K., Schukken, Y. K., Fortes, E. D., Ho, A. J., Her, Z., Grohn, Y. T., et al., 2014: Ecology of transmission of Listeria monocytogenes infecting ruminants and in the farm environment. Appl. Environ. Microbiol., 70, 8, 4458-4467. DOI: 10.1128/AEM.70.8.4458-4467.2004.

38. Okorie-Kanu, O. J., Anyanwu, M. U., Ezenduka, E. V., Mgbeahuruike, A. C., Okorie-Kanu, C. O., Ugwuijem, E. E., et al., 2020: Occurrence and antibiogram of Listeria species in raw pork, beef, and chicken meats marketed in Enugu State, Southeast Nigeria. Vet. World, 13, 2, 317-325. DOI: 10.14202/ vetworld.2020.317-325.

39. Olaimat, A. N., Al-Holy, M. A., Shahbaz, H. M., Al-Nabulsi, A. A., Ghoush, M. H. A., Osaili, T. M., 2018: Emergence of antibiotic resistance in Listeria monocytogenes isolated from food products: a comprehensive review. Compr. Rev. Food Sci. Food Saf., 17, 1277-1292. DOI: 10.1111/1541-4337.12387.

40. O'Neill, J., 2014: Antimicrobial resistance: Tackling a crisis for the health and wealth of nations. In The Review on Antimicrobial Resistance. London, UK, 1-20. https://www.amr-review.org. Accessed on 5th June, 2020. 
41. Pan, Y. Jr., Breidt, F., Kathariou, S., 2006: Resistance of Listeria monocytogenes biofilms to sanitizing agents in a simulated food processing environment. Appl. Environ. Microbiol., 72, 7711-7717. DOI: 10.1128/AEM.01065-06.

42. Pawar, D., Rossman, M., Chen, J., 2005: Role of curli fimbriae in mediating the cell of enterohaemorrhagic Escherichia coli to attach to abiotic surfaces. J. Appl. Microbiol., 99, 418-425. DOI: 10.1111/j.1365-2672.2005.02499.x.

43. Peter, A., Umeh, E., Azua, E., Obande, G., 2016: Prevalence and antimicrobial susceptibility of Listeria monocytogenes isolated from beef, pork, and chicken sold in Makurdi Metropolis. Br. Microbiol. Res. J., 14, 5, 1-7. DOI: 10.9734/BMRJ/ 2016/25663.

44. Podpečan, B., Pengov, A., Vadnjal, S., 2007: The source of contamination of ground meat for production of meat products with bacteria Staphylococcus aureus. Slov. Vet. Res., 44, 25-30.

45. Porto, E., Eiroa, M., 2001: Occurrence of Listeria monocytogenes in vegetables. Dairy Food Environ. Sanit., 21, 282-286.

46. Puga, C. H., Dahdouh, E., SanJose, C., Orgaz, B., 2018: Listeria monocytogenes colonizes Pseudomonas fluorescens biofilms and induces matrix over-production. Frontier Microbiol., 9, 1706, 1-12. DOI: 10.3389/fmicb.2018.01706.

47. Sarangi, L. N., Panda, H. K., 2012: Isolation, characterization and antibiotic sensitivity test of pathogenic Listeria species in livestock, poultry and farm environment in Odisha. Indian J. Anim. Res., 46, 3, 242-247.

48. Shirima, G. M., Fitzpatrick, J., Kunda, J. S., Mfinanga, G. S., Kazwala, R. R., Kambarage, D. M., et al., 2010: The role of livestock keeping in human brucellosis trends in livestock keeping communities in Tanzania. Tanzanian J. Hlth. Res., 12, 3, 203-207. DOI: 10.4314/thrb.v12i3.51261.
49. Thrusfield, M. V., 2007: Veterinary Epidemiology. 3rd edn., Blackwell, Oxford, $282 \mathrm{pp}$.

50. United Nations Departments of Economic and Social Affairs. World Urbanization Prospects, 2012: The 2011 Revision. United Nations Departments of Economic and Social Affairs (UNDESA), Population Division. Accessed on 20th August, 2019). https://www.un.org/en/development/desa/population/publications/pdf/urbanization/W UP2011_Report.pdf.

51. Voronina, O. L., Ryzhova, N., Kunda, M. S., Kurnaeva, M. A., Semenov, A. N., Aksenova, E. I., et al., 2015: Diversity and pathogenic potential of Listeria monocytogenes isolated from environmental sources in the Russian Federation. Int. J. Modern. Eng. Res., 5, 3, 5-15.

52. Wadhwa, D. R., Smith, M. A., 2017: Pregnancy-related listeriosis. Birth Defects Res., 109, 324-335. DOI: 10.1002/ bdr2.1012.

53. Wardrop, N. A., 2016: Integrated epidemiology for vector-borne zoonoses. Trans. Roy. Soc. Trop. Med. Hyg., 110, 87-89. DOI: $10.1093 /$ trstmh/trv115.

54. Whitman, K. J., Bono, J. L., Clawson, M. L., Loy, J. D., Bosilevac, J. M., Arthur, T. M., et al., 2020: Genomic-based identification of environmental and clinical Listeria monocytogenes strains associated with an abortion outbreak in beef heifers. BMC Vet. Res., 16, 70. DOI: 10.1186/s12917-0202276-z.

55. World Health Organization, 2018: Listeriosis Fact Sheet. WHO 2018. Accessed on 16th December, 2019. https://www. who.int/news-room/fact-sheets/detail/listeriosis/.

Received January 4, 2021

Accepted April 14, 2021 